\title{
Nerve-injury induced changes to GluR1 and GluR2/3 sub-unit expression in area $3 b$ of adult squirrel monkeys: developmental recapitulation?
}

\author{
Todd M. Mowery ${ }^{*}$ and Preston E. Garraghty ${ }^{1,2}$ \\ Department of Psychological and Brain Sciences, Indiana University, Bloomington, IN, USA \\ 2 Program in Neuroscience, Indiana University, Bloomington, IN, USA
}

\section{Edited by:}

Neeraj Jain, National Brain Research

Centre, India

Reviewed by:

Patricia Gaspar, INSERM, France John Wall, The University of Toledo, USA

\section{${ }^{*}$ Correspondence:}

Todd M. Mowery, Department of Psychological and Brain Sciences, Indiana University, 1101 E. 10th Street, Bloomington, IN 47405, USA e-mail: tmmowery@indiana.edu
The primate somatosensory system provides an excellent model system with which to investigate adult neural plasticity. Here, we report immunohistochemical staining data for the GluR1 and GluR2/3 AMPA receptors subunits in somatosensory area 3b 1 week after median nerve compression in adult squirrel monkeys. We find transcortical increases in the staining intensity of GluR1 AMPAR subunits and transcortical decreases in GluR2/3 AMPAR subunits. This pattern of change in the staining intensity of these subunits differs from the changes one would expect if the deprived cortical neurons were undergoing homeostatic synaptic scaling, or from ones that would follow N-methyl-d-aspartate (NMDA) receptor-mediated long-term potentiation. Indeed, this pattern of change appears to recapitulate proportions that exist early in development as if the deprived cortex has reverted to an immature state. We suggest that this state represents yet another stage of peripheral nerve injury-induced reorganization in adult primate somatosensory cortex, and may well be essential for subsequent NMDA receptor-mediated plasticity.

Keywords: sensory plasticity, AMPA, GluR1, GluR2/3, reorganization

\section{INTRODUCTION}

The fact that the adult brain retains a remarkable degree of flexibility to respond to alterations in the pattern of inputs it receives is beyond dispute. While there were scattered earlier reports of adult plasticity (e.g., Brown and Salinger, 1975; Creutzfeldt and Heggelund, 1975), they were largely ignored by the scientific community until the seminal publications of Merzenich, Kaas and colleagues in the early 1980s (Merzenich et al., 1983a,b). Since then research in the general area of adult neural plasticity has exploded. A number of model systems have been employed in studying neural plasticity in the mature brain, with the primate somatosensory system proving quite fertile (e.g., Churchill et al., 1998, 2001; Florence et al., 1998, 2000; Garraghty and Kaas, 1991; Garraghty et al., 2006; Kaas et al., 1999; Merzenich et al., 1984; Pons et al., 1991; Schroeder et al., 1997), particularly given the likelihood of greater potential for translational relevance (e.g., Courtine et al., 2007).

Following the initial set of more phenomenological reports (Merzenich et al., 1983a,b, 1984), attention shifted to a search for the mechanisms of plasticity (e.g., Allard et al., 1991; Garraghty et al., 1991, 1994; Recanzone et al., 1992; Xerri et al., 1994). The early, pioneering experiments of Merzenich et al. (1983a,b) showed that transection and ligation of the median nerve, which deafferentates the thumb side of the glabrous surface of the hand, was followed by a reorganization of the cortical map in which the deprived cortex regained responsiveness to tactile stimulation of adjacent skin surfaces on the hand with intact innervation. Moreover, this reorganization was shown to proceed in no fewer than two stages, an immediate, unmasking stage in which neurons in deprived cortex expressed new receptive fields directly after the nerve transection, and a more protracted second stage in which neurons throughout the remaining deprived cortex regained responsiveness to tactile stimulation over the ensuing days to weeks (Merzenich et al., 1983b).

The immediate plasticity is assumed to reflect the unmasking of tonically suppressed inputs due to a relaxation in afferentdriven inhibition, and we have reported reductions in $\mathrm{GABA}_{\mathrm{A}}$ receptor binding in layer IV of deprived area $3 b$ cortex within hours of nerve transection (Garraghty et al., 2006; Wellman et al., 2002), a finding that is consistent with a down-regulation of inhibition. We have shown that the latter stage of reorganization is prevented if $N$-methyl-D-aspartate (NMDA) glutamatergic receptors are blocked (Garraghty and Muja, 1996). The unmasking phase of reorganization, on the other hand, occurs whether NMDA receptors are blocked or not (Myers et al., 2000). These latter observations have prompted us to draw parallels between this nerve injury-induced model of neural plasticity and NMDA receptor-dependent long-term potentiation (LTP) in the hippocampus (Garraghty and Muja, 1996; Garraghty et al., 2006; Myers et al., 2000). Consistent with this idea, we have shown that $\alpha$-amino3-hydroxy-5-methyl-4-isoxazolepropionate (AMPA) receptors are up-regulated 1-2 months after median nerve transection (Garraghty et al., 2006), which parallels reports involving hippocampal LTP (e.g., Maren et al., 1993; Tocco et al., 1992).

Our earlier report involved the use of receptor autoradiography, and consequently, could provide no information regarding possible changes in the subunit composition of the receptors being quantified. In the present experiments, we have quantified the immunohistochemical staining of GluR1 and GluR2/3 AMPA receptor subunits in deprived cortex 1 week following median nerve compression to determine whether early changes in AMPA receptor subunit expression contribute to the second phase of reorganization. 


\section{MATERIALS AND METHODS NERVE COMPRESSION}

We report data from three adult squirrel monkeys (Saimiri sciureus). Animals were maintained on isoflurane anesthesia 2-4\% throughout the surgery. The arm was shaved between the wrist and elbow on the ventral surface of the forearm. An initial incision was made along the midline of the ventral forearm around $70 \mathrm{~mm}$ from the wrist. Under microscopic view, the median nerve was located and isolated by blunt dissection and elevated. Hemostats were then applied to the nerve at approximately a $45^{\circ}$ angle and held in place for $30 \mathrm{~s}$. This was repeated three times distally over the span of a few $\mathrm{mm}$. The hemostat was then rotated $90^{\circ}$, and applied four times to create a crossing pattern to ensure complete compression of the nerve. The nerve was then repositioned, the skin was sutured over the incision site, and the monkey was allowed to recover. All protocols were approved by the Institutional Animal Care and Use Committee (IACUC).

\section{IMMUNOHISTOCHEMISTRY}

One week after nerve compression, animals were anesthetized with isoflurane gas and immediately transcardially perfused with cold $0.9 \%$ saline solution followed by $400 \mathrm{ml}$ of $4 \%$ paraformaldehyde in $0.1 \mathrm{M}$ phosphate buffer ( $\mathrm{pH}$ 7.4). Following perfusion the brains were extracted and the left and right somatosensory cortices were dissected out and post-fixed for $2 \mathrm{~h}$ in cold fixative (4\% paraformaldehyde in $0.1 \mathrm{M}$ phosphate buffer ( $\mathrm{pH}$ 7.4). Tissue was then cryoprotected overnight in $30 \%$ sucrose in phosphate buffer ( $\mathrm{pH} 7.4$ ).

Frozen $40 \mu \mathrm{m}$ sections of the pre and post-central gyri were cut in a parasagittal plane and collected in staining nets in phosphate buffer. Sections that were clearly within the central sulcus were kept for immunohistochemistry. After sectioning, tissue was washed in immuno-phosphate buffer and then incubated in blocking solution for $30 \mathrm{~min}$ and then hydrogen peroxide $0.01 \%$ for $15 \mathrm{~min}$ at room temperature to reduce endogenous peroxidase activity. Tissue sections were then incubated overnight at $4^{\circ} \mathrm{C}$ in antisera containing either rabbit phosphor-GluR1 (1:1000 Chemicon) or rabbit GluR2/3 (1:1000 Affinity Bio Reagents), and then washed three times for $10 \mathrm{~min}$ in IPB before being incubated in goat antirabbit biotinylated antibodies for $1 \mathrm{~h}$ at room temperature. Sections were again washed three times for $10 \mathrm{~min}$ in PBS, then incubated in $\mathrm{ABC}$ solution for $1 \mathrm{~h}$ (ABC Elite Kit, Vector), washed again three times for $10 \mathrm{~min}$ in acetate-imidazole buffer, and then incubated in acetate-imidazole buffer containing nickel sulfate, $0.5 \mathrm{mg} / \mathrm{ml}$ 3, $3^{\prime}$-diaminobenzidine- $4 \mathrm{HCI}$ (DAB, Vector) and $0.01 \% \mathrm{H}_{2} \mathrm{O}_{2}$ for $8 \mathrm{~min}$. Sections were then washed three times in PBS for $10 \mathrm{~min}$, mounted on gelatin coated glass slides and dried overnight. Once dry, the sections were dehydrated in ascending ethanols, cleared with xylenes, and then cover-slipped. The antibodies used in this experiment bind to specific sites on the GluR1 (Ser831) and GluR2/GluR3 (C terminal) subunits and no cross-reactivity has been reported. Positive and negative controls were generated by omitting the primary or secondary antibody. These sections did not reveal the presence of any binding.

\section{QUANTIFICATION OF RECEPTOR SUBUNIT STAINING INTENSITY}

Immunohistochemical quantification of tissue sections were carried out at $1480 \times$ under bright-field illumination using a microscope
(Nikon Eclipse 80i; Nikon Instruments; Melville, NY, USA) and the Stereo Investigator (MBF Bioscience; Williston, VT, USA) software. A tracing grid was constructed with Nissl-stained tissue that consisted of an approximation of the cortical layers I through VI. The 1-mm wide tracing grid was aligned with the median nerve area $3 \mathrm{~b}, 1 \mathrm{~mm}$ lateral to the central sulcus spanning across cortical regions corresponding to glabrous median nerve regions of digits 1-3 (Garraghty et al., 2006; Sur et al., 1982). Once the tracing grid was placed, the user moved throughout the predefined cortical layers (II-VI) tracing the somata of user defined neurons. Aside from the tracing grid, layers were generally discernable to the trained observer based on changes in neural phenotype.

Tissue was originally sliced at $40 \mu \mathrm{m}$, but following staining procedures and cover-slipping had a final tissue thickness of around 25-30 $\mu \mathrm{m}$. Per layer, the microscope was focused down through the $z$-axis to depth of around $15 \mu \mathrm{m}$ where uniformly stained neurons within the plane of focus were randomly selected and traced $(\sim 30)$. Additionally, within each layer, neuropil measurements were taken $(\sim 10)$. These were operationally defined as regions of tissue in which $z$-axis scrolling from the top to the bottom of the tissue revealed no somata.

Finally white matter measurements were collected (below layer VI 5), that consisted of regions in which no antibody binding had occurred. Four to five sections were measured per antibody per hemisphere per animal generating around 120-150 soma measurements and 40-50 neuropil measurements per hemisphere per antibody.

The Stereo Investigator software's luminance function was used to quantify staining intensity of the traced contours (representative neurons, neuropil, and white matter). The luminance function measures the amount of light passing through the tissue per square $\mu \mathrm{m}$ of contour $(0=$ black and $256=$ white $)$, and is used as an indirect measurement of subunit expression. Previous studies by our colleagues using immunohistochemical procedures and similar bright-field densitometry quantification methods show that densitometry/luminance quantification of immunohistochemically labeled tissue is a reliable measure of protein expression (Osborne et al., 2007; Wilber et al., 2007, 2009). Staining intensity data were generated by taking a ratio of the average staining intensity per layer to the average staining intensity of the white matter. Great effort was made to maintain light parameters within the Stereo Investigator software between users and user sessions.

\section{RESULTS}

\section{GluR1 AND GIUR2/3 STAINING INTENSITY: CONTROL MEASUREMENTS}

Figure 1 presents photomicrographs of neurons expressing GluR1 and GluR2/3 subunits from layers II-VI of intact and control hemispheres. The left side of the figure shows immunolabeling for both subunits, while the right side of the figure shows higher powered images of labeled neurons within deprived and control hemispheres. This figure demonstrates the comparative increases in GluR1 staining intensity and comparative decreases in GluR2/3 staining intensity in deprived hemisphere (right hemisphere). Figure 2 presents the averages of raw intensity measurements for GluR1 and GluR2/3 AMPA receptor subunits for soma and neuropil in control area $3 \mathrm{~b}$ median nerve cortex as a function of cortical layer. Statistically, we find that the distributions of GluR1 and GluR2/3 


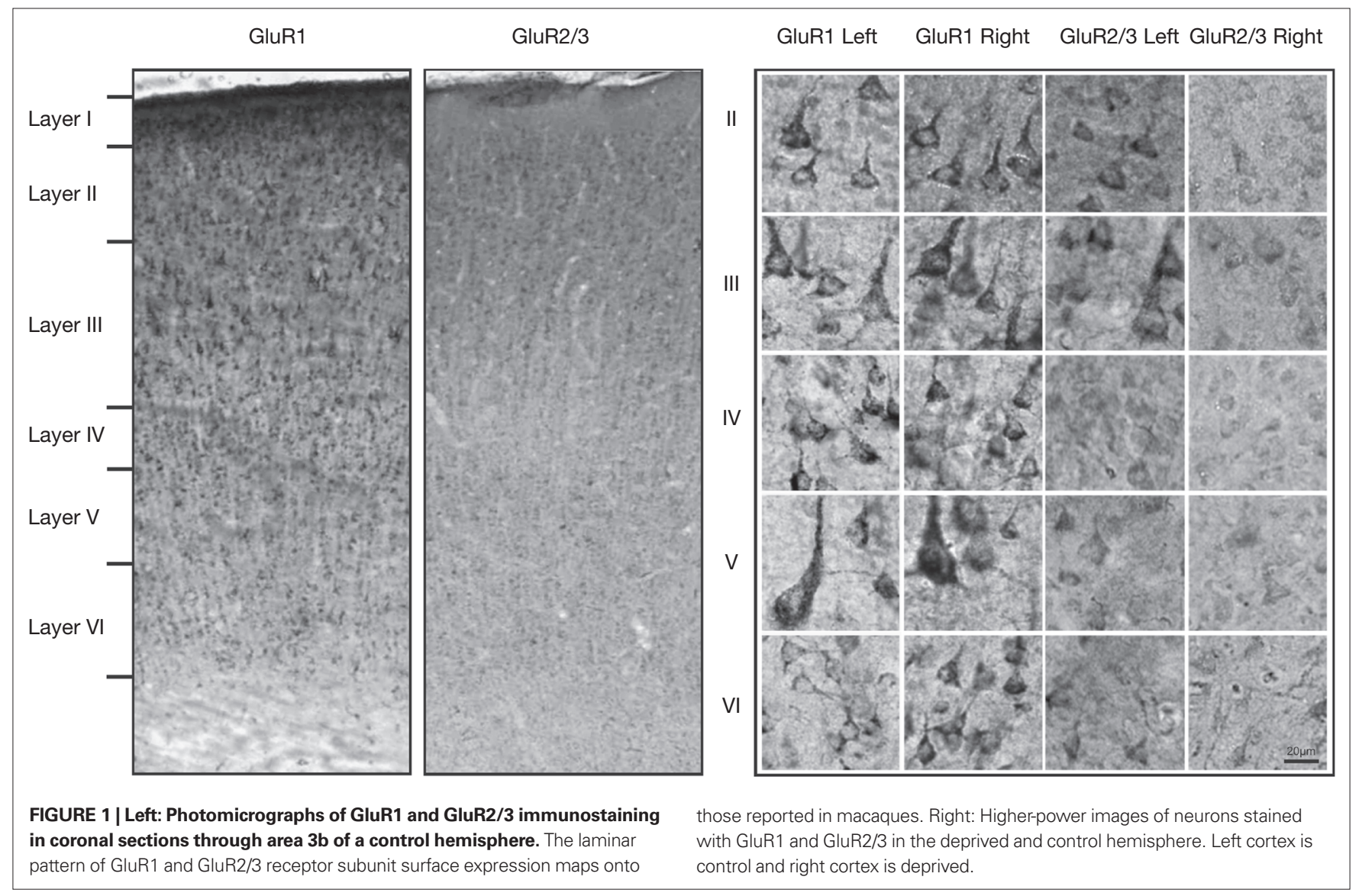

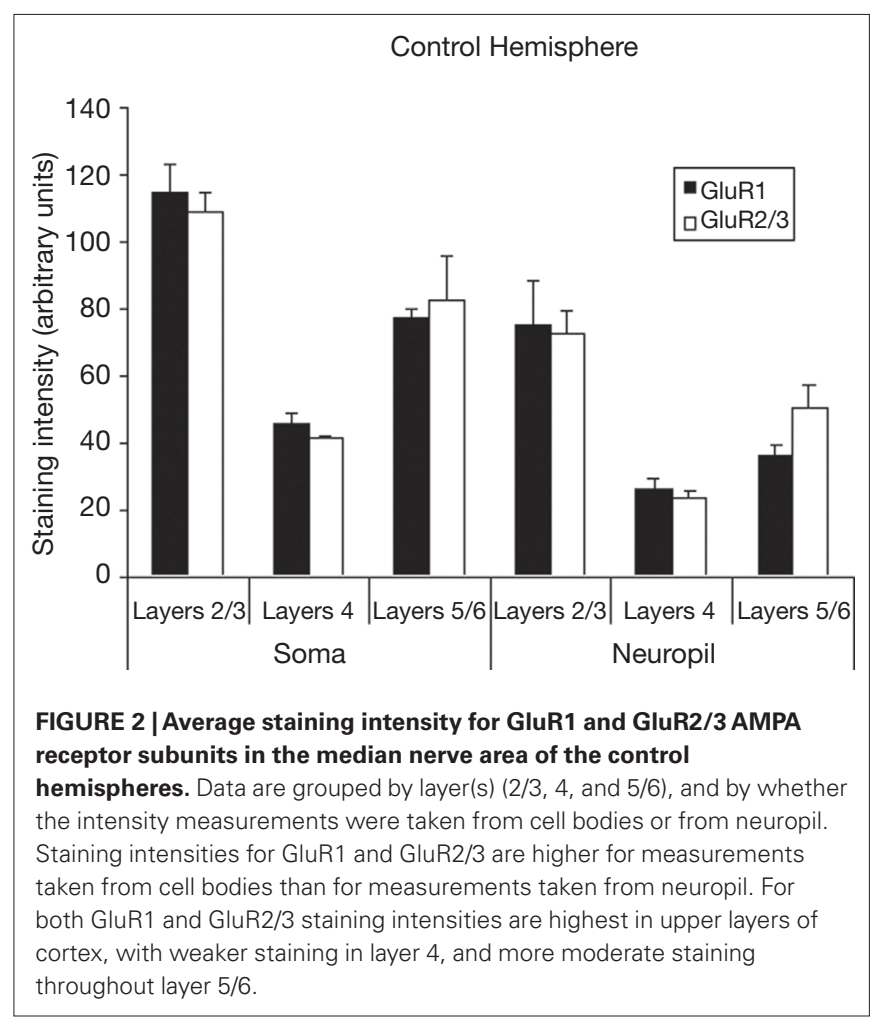

AMPA receptor subunit staining intensities are comparable across the layers of cortex for both cellular and neuropil measurements; and that is there is no main effect for receptor subunit $[F(1,24)=0.023, p>0.85]$. There is, however, a significant difference in the expression of both GluR1 and GluR2/3 receptor subunit staining intensities between the somatic and neuropil measurements across all layers $[F(1,24)=80.08, p<0.001]$. This finding becomes more apparent when averaging somatic staining intensities for GluR1 (47.2 \pm 2.28$)$ and GluR2/3 (45.8 \pm 1.63$)$ receptor subunits, compared to neuropil measurements which are $27.5 \pm 3.45$ and $28.2 \pm 2.15$ for the GluR1 and GluR2/3 subunits respectively. The data as presented in Figure 2 also underscore our finding of equivalent staining intensities of these receptor subunits throughout the median nerve cortex. Finally, we find a significant difference in the staining intensities of GluR 1 and GluR2/3 receptor subunits across different layers of the sensory cortex $[F(2,24)=20.93, p<0.001]$. Post-hoc analysis (Scheffé) reveals that there is greater expression of both subunits in layers $2 / 3$ than in either layer 4 or layers $5 / 6$ (both $p$ 's $<0.001$ ), whereas the expression does not differ between layer 4 and layers $5 / 6(p>0.35)$.

\section{EFFECTS OF DEPRIVATION: GIUR1 STAINING INTENSITY}

Figure 3 compares the staining intensity means for GluR1 subunits between control and deprived hemispheres. We find that deprivation results in an increase in GluR1 staining intensity in the deprived 


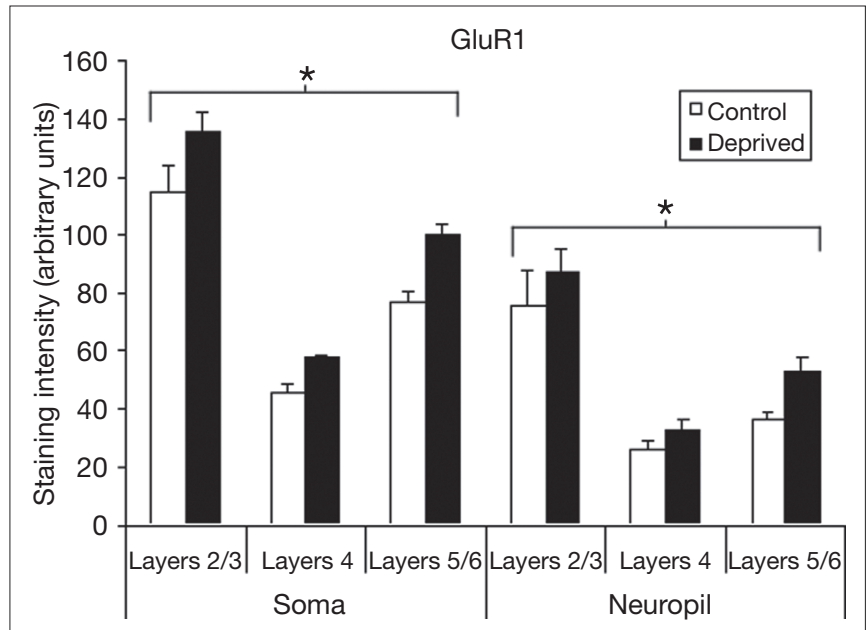

FIGURE 3 | Comparison of average staining intensities for GluR1 in deprived and control hemispheres. Conventions are the same as in

Figure 2. GluR1 staining intensities are higher in the deprived hemisphere in all layers for both cell body and neuropil measurements $\left({ }^{*} p<0.001\right)$.

hemisphere relative to control, with this effect being relatively stable across cortical layers and somatic versus neuropil measures $[F(1,12)=159.65, p<0.001]$. Because this deprivation-induced increase in GluR1 staining intensity is so symmetrically distributed, we also find a significant main effect for layer $[F(2,12)=22.14$, $p<0.001$ ], with post-hoc comparisons again showing staining intensity to be higher in layers $2 / 3$ than in layer 4 or layers $5 / 6$ (Scheffé, both $p$ 's $<0.05$ ), with no difference between layer 4 and layers 5/6 $(p>0.05)$. Finally, the difference between somatic and neuropil staining intensities is again present $[F(1,12)=46.51, p<0.001]$.

\section{EFFECTS OF DEPRIVATION: GIUR2/3 STAINING INTENSITY}

Figure 4 compares the staining intensity means for GluR2/3 subunits between control and deprived hemispheres. For this subunit, we find that deprivation results in a decrease in staining intensity, and that this decrease is relatively stable across cortical layers and somatic versus neuropil measures $[F(1,12)=93.15, p<0.001]$. As we did for the GluR1 subunit, we also find a significant main effect for layer $[F(2,12)=22.14, p<0.001]$, with post-hoc comparisons again showing staining intensity to be higher in layers $2 / 3$ than in layer 4 or layers $5 / 6$ (Scheffé, both $p$ 's $<0.001$ ), with no difference between layer 4 and layers 5/6 $(p>0.05)$. Finally, the difference between somatic and neuropil staining intensities is again present $[F(1,12)=78.00, p<0.001]$.

\section{EFFECTS OF DEPRIVATION ON AMPA RECEPTORS AS INDEXED BY THE SUMMED STAINING INTENSITIES OF GIUR1 AND GIUR2/3 STAINING}

Figure 5 compares the average summed staining for GluR1 and GluR2/3 subunits in the deprived and intact hemispheres. The $7 \%$ difference between the deprived and non-deprived measurements is not statistically significant $(t=2.6, p>0.10)$. Thus, to the extent that these measures can be used as an estimate of AMPAR expression, these results could suggest that AMPAR trafficking is geared towards changes in functionality through subunit composition as opposed to general scaling 1 week following median nerve compression.

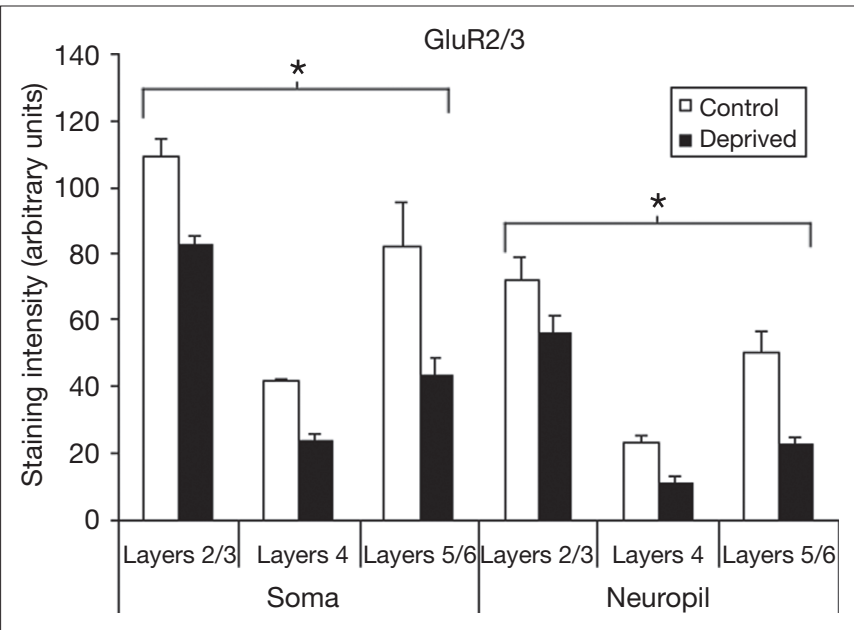

FIGURE 4 | Comparison of average staining intensities for GluR2/3 in deprived and control hemispheres. Conventions are the same as in Figure 2. GluR2/3 staining intensities are lower in the deprived hemisphere in all layers for both cell body and neuropil measurements $\left({ }^{*} p<0.001\right)$.

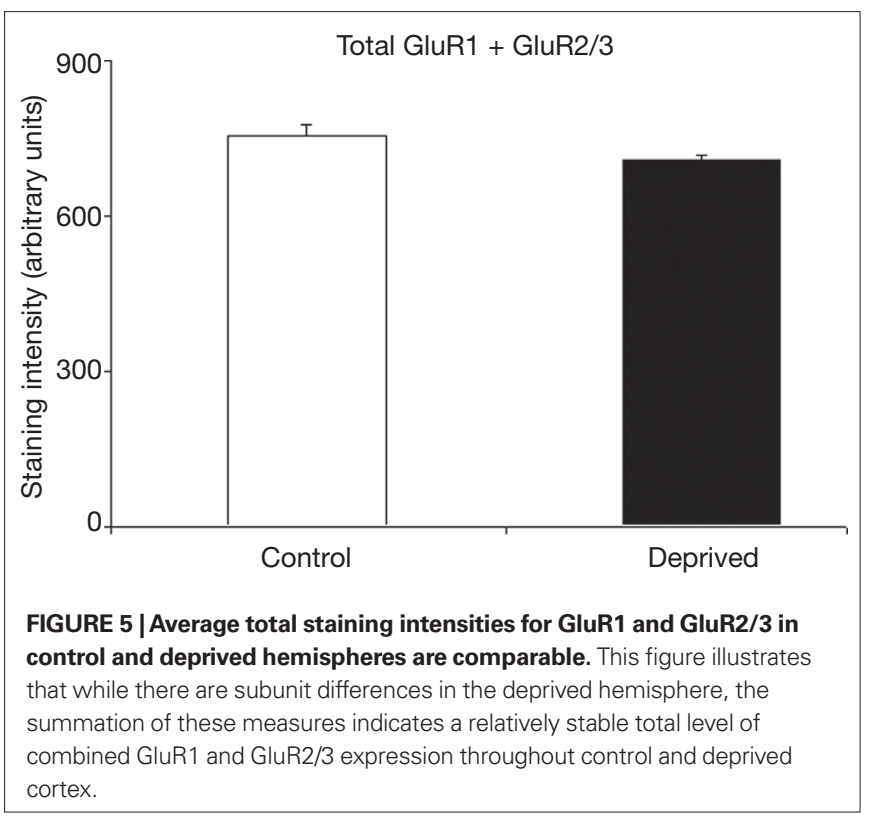

\section{DISCUSSION}

We report several findings based on quantitative immunohistochemical staining data for AMPA receptor subunits GluR1 and GluR2/3 in area $3 \mathrm{~b}$ of squirrel monkey somatosensory cortex. (1) In intact area $3 b$, the staining intensities of these subunits are nearly identical. (2) In control area 3b, both GluR1 and GluR2/3 staining intensities are highest in layers $2 / 3$, and roughly equivalent in layer 4 and layers 5/6. (3) In deprived area 3b, GluR1 staining intensity is increased relative to non-deprived measurements across all cortical layers for both somata and neuropil. (4) In deprived area $3 b$, GluR2/3 staining intensity is decreased relative to control values across all cortical layers for both somata and neuropil. Bilateral consequences of unilateral sensory manipulations have been rather widely reported (e.g., Calford and Tweedale, 1990, 1991; 
Clarey et al., 1996; Kozin et al., 1976; Oaklander and Belzberg, 1997; Oaklander and Brown, 2004; Vergara-Aragon et al., 2003), with the ipsilateral effects tending to mirror those found contralaterally (e.g., Calford and Tweedale, 1990; Oaklander and Brown, 2004). In the present study, there are clear differences between the contralateral and ipsilateral hemispheres, suggesting either that there are no changes in the ipsilateral cortex or that they are in the opposite direction of those in the contralateral cortex. We favor the first of these possibilities as we have shown using receptor autoradiography that changes in AMPA receptor binding levels at 1-2 months after nerve injury are confined to the contralateral hemisphere (Garraghty et al., 2006).

\section{CONTROL MEASUREMENTS}

Our finding of roughly equal staining intensities for Glur1 and Glur2/3 AMPA receptor subunits is in contrast with the data reported by Muñoz et al. (1999) using in situ hybridization of GluR1, 2, and 3 mRNAs. While our methods do not permit us to distinguish between GluR2 and GluR3 subunits, examination of the Muñoz et al. (1999; Figure 1A) data from macaque monkeys finds the summed mRNA expression levels of GluR2 and GluR3 to be considerably higher than that of GluR1. This difference could reflect a New versus Old World primate species difference (though this seems unlikely; see Garraghty et al., 2006), or more likely, the difference between the methods of subunit measurement and quantification. Recognizing the differences in the measure techniques employed, the laminar distributions of GluR 1 and GluR2/3 immunostaining intensities reported here are in general agreement with the findings of Muñoz et al. (1999). Their optical density distributions for GluR1-3 (see their Figure 5) roughly map onto our control data layer by layer (see Figure 2). Furthermore, their micrographs of GluR1-3 immunohistochemical staining (their Figure $6 \mathrm{~B}$ and $6 \mathrm{G}$ ) generally reflect the staining seen in our images (see Figure 1). Thus, the pattern of GluR1-3 expression in squirrel monkey area $3 \mathrm{~b}$ generally maps onto that found in Old World macaque monkeys.

\section{EFFECTS OF DEPRIVATION}

One week after median nerve compression, we find increases in immunohistochemical staining intensity for the GluR1 AMPA receptor subunit, and concurrent decreases in staining intensity for the GluR2/3 AMPA receptor subunits throughout all layers of deprived area $3 \mathrm{~b}$. This pattern of change differs from ones that have been reported in the emerging literature on homeostatic plasticity, where in, various models of homeostatic AMPA receptor trafficking some investigators have reported increases in both GluR1 and GluR2 subunits (e.g., Hou et al., 2008; Wierenga et al., 2005) while others have reported increases in GluR1 with no changes in GluR2 (e.g., Ju et al., 2004; Sutton et al., 2006; Thiagarajan et al., 2005). These paradigms do provide important examples of AMPAR mechanics at focalized synapses; however, it is difficult to assess any absolute connection between these in vitro cell studies and the more global data generated in our in-vivo model of sensory deprivation/reorganization. Furthermore all of these studies used immature tissue (ED 18 to PND 4), and so the actual relationship to our experiment, which investigates the response of adult neural networks to deprivation and reorganization, remains unknown. With this in mind, recent evidence demonstrates that manifestations of homeostatic plasticity in juveniles and adults have specific nuances that differ from cell cultures (Echegoyen et al., 2007).

Even more relevant to our sensory reorganization model are in-vivo applications concerning experience dependent plasticity. While studies investigating experience dependent glutamate receptor mechanisms share some aspects with our results, they do not fully agree with the pattern of subunit expressions seen in the present study. Wright et al. (2008) used a spared whisker paradigm to study the in-vivo effects of experience dependent depression and its relationship to GluR subunit changes. While they do report significant decreases in GluR2 and GluR3 subunits, there are no significant changes in GluR1 expression (see Supplementary Material Figure 4a; Wright et al., 2008). Reorganization of the median nerve cortex may well involve some of the same experience dependent mechanisms of GluR mediated LTD (Allen et al., 2003), and LTP (Takahashi et al., 2003), but the extent to which reorganization relies on experience dependent mechanisms, exactly how and when it is induced, and what role, if any, homeostatic plasticity plays in its propagation remains unclear. Again, it is important to make distinctions between in-vivo studies that use neonates and adolescent subjects, as opposed to adults, because of the known changes in receptor subunit populations reported during development, as well as, differences that may arise through cross-species studies (mouse versus rat versus monkey).

The increase in Glur1 staining intensity and concomitant decrease in GluR2/3 staining intensity found here in deprived cortex 1 week after nerve compression results in an apparent pattern of subunit expression that is quite comparable to the one shown to exist early in development (e.g., Eybalin et al., 2004; Ho et al., 2007; Kumar et al., 2002). We have suggested previously (Garraghty et al., 2006) that adult monkey somatosensory cortex retains features that are used to shape neural developmental outcomes in other structures. The present result suggests that mature primate somatosensory cortex might also possess mechanisms that permit it to recapitulate developmental processes when challenged to undergo reorganization. Interestingly, genetic screening of adult somatosensory cortex collected from one monkey within hours of nerve injury revealed the up-regulation of a number of genes (e.g., neuroregulin) that play prominent roles in development (Prieto et al., unpublished observations).

\section{A "HIDDEN" STAGE OF REORGANIZATION?}

The present data reveal no distinct evidence of NMDA receptormediated plasticity at this survival duration. The cortical reorganization that follows peripheral nerve injury in monkeys proceeds via an immediate unmasking phase followed by a more protracted secondary stage during which neurons in the initially unresponsive regions of deprived cortex become responsive to novel cutaneous stimulation (Merzenich et al., 1983b; Myers et al., 2000). We have shown previously that this second phase of reorganization can be prevented by blocking NMDA receptors (Garraghty and Muja, 1996), and have drawn some parallels between this secondary phase of plasticity and NMDA receptor-dependent LTP in the hippocampus (Garraghty and Muja, 1996; Garraghty et al., 2006; Myers et al., 2000). Most notably, we have reported an increase in AMPA receptor autoradiographic binding at post-nerve injury survival 
durations when the putative second phase of reorganization has been completed (Garraghty et al., 2006), but this was not seen at early (i.e., 0-3 days post-nerve injury) survival durations. While there is no direct evidence that subunit expression can be used as a measure of receptor frequency, the increase in the GluR1 subunit staining intensity is balanced reasonably well by the decrease in GluR2/3 staining intensity such that the summed intensities of GluR1 and GluR2/3 staining in the deprived and non-deprived hemispheres are quite comparable. We tentatively conclude that these changes in receptor subunit populations have functional consequences for network activity beyond that which would be associated with increased membrane expression of AMPA receptors found at later stages of reorganization (Garraghty et al., 2006). These qualitative changes in AMPAR composition would have been hidden in our previous studies, and will be explored in further research.

We, and others, have previously described the reorganizational changes in primate cortical somatotopy that follow peripheral nerve injury as proceeding in two stages, one immediate and one more protracted (e.g., Garraghty and Muja, 1996; Merzenich et al., 1983b; Myers et al., 2000). It is important to note that this characterization was based solely on electrophysiological mapping data. The present findings suggest the existence of yet another stage of reorganization during which there is a shift in AMPA receptor phenotype indicative of a return to immature AMPAR function. In their elegant study of the time-course of cortical reorganization after sciatic nerve injury in adult rats, Cusick et al. (1990) noted what they thought might be an intermediate stage of reorganization that intervened between the immediate unmasking phase and a later wave of plasticity (see Figure 2; Cusick et al., 1990). They suggested that "early and late cortical changes both involve local synaptic reorganization, but that late, slowly developing cortical changes do not occur unless neurons and synapses are appropriately conditioned by a 'priming' sequence of earlier changes" (emphasis added; Cusick et al., 1990, p. 357). While the time-course of reorganization in rat cortex after sciatic nerve injury is substantially longer than that in monkey cortex after median nerve injury, the intermediate stage of plasticity suggested here could reflect such a "priming sequence" that sets the stage for the subsequent NMDA receptor-mediated reorganization (cf., Hagemann et al., 1998). We posit that this intermediate stage reflects a return to a pseudo-developmental state, much as has been reported to accompany cortical infarct both in terms of human clinical and brain imaging observations, and in terms of protein expression measures in animal models (for review, see Cramer and Chopp, 2000). The hallmark of this recapitulation of ontology is the return to earlier forms of synaptic transmission, which include $\mathrm{Ca}++$ permeable AMPARs, and a peak of cortical excitatory potential seen 7-10 days post injury in the peri-infract cortical regions (Hagemann et al., 1998). Such changes in deprived primate cortex at this post-nerve injury survival duration would presumably facilitate, or be essential for the NMDA receptor-dependent phase of reorganization (Garraghty and Muja, 1996).

\section{ACKNOWLEDGEMENTS}

Supported by National Institutes of Health/National Institute of Neurological Disorders and Stroke; Grant number: NS37348.

\section{REFERENCES}

Allard, T., Clark, S. A., Jenkins, W. M., and Merzenich, M. M. (1991). Reorganization of somatosensory area $3 \mathrm{~b}$ representations in adult owl monkeys after digital syndactyly. J. Neurophysiol. 66, 1048-1058.

Allen, C. B., Celikel, T., and Feldman, D.E. (2003). Long-term depression induced by sensory deprivation during cortical map plasticity in vivo. Nat. Neurosci. 6, 291-299.

Brown, D., and Salinger, W. (1975). Loss of X-cells in lateral geniculate nucleus with monocular paralysis: neural plasticity in the adult cat. Science 189, 1011-1012.

Calford, M. B., and Tweedale, R. (1990). Interhemispheric transfer of plasticity in the cerebral cortex. Science 249, 805-807.

Calford, M. B., and Tweedale, R. (1991). Immediate expansion of receptive fields of neurons in area $3 \mathrm{~b}$ of macaque monkeys after digit denervation. Somatosens. Mot. Res. 8, 249-260.

Churchill, J. D., Arnold, L. L., and Garraghty, P. E. (2001). Somatotopic reorganization in the brainstem and thalamus following peripheral nerve injury in adult primates. Brain Res. 910, 142-152.
Churchill, J. D., Muja, N., Myers, W. A., Besheer, J., and Garraghty, P. E. (1998). Somatotopic consolidation: a third phase of reorganization after peripheral nerve injury in adult squirrel monkeys. Exp. Brain Res. 118, 189-196.

Clarey,J.C., Tweedale,R., andCalford, M. B. (1996). Interhemispheric modulation of somatosensory receptive fields: evidence for plasticity in primary somatosensory cortex. Cereb. Cortex 6, 196-206.

Courtine, G., Bunge, M. B., Fawcett, J. W., Grossman, R. G., Kaas, J. H., Lemon, R., Maier, I., Martin, J., Nudo, R. J., Ramon-Cueto, A., Rouiller, E. M., Schnell, L., Wannier, T., Schwab, M. E., and Edgerton V. R. (2007). Can experiments in nonhuman primates expedite the translation of treatments for spinal cord injury in humans? Nat. Med. 13, 561-566.

Cramer, S. C., and Chopp, M. (2000). Recovery recapitulates ontogeny. Trends Neurosci. 23, 265-271.

Creutzfeldt, O., and Heggelund, P. (1975). Neural plasticity in visual cortex of adult cats after exposure to visual patterns. Science 188, 1025-1027.

Cusick, C. G., Wall, J. T., Whiting, J. H. Jr, and Wiley, R. G. (1990). Temporal progression of cortical reorganization following nerve injury. Brain Res. 537 , 355-358.

Echegoyen, J., Neu, A., Graber, K. D. and Soltesz, I. (2007). Homeostatic plasticity studied using in vivo hippocampal activity-blockade: synaptic scaling, intrinsic plasticity and agedependence. PLoS ONE 8, e700.

Eybalin, M., Caicedo, A., Renard, N. Ruel, J., and Puel, J. L. (2004). Transient Ca2+-permeable AMPA receptors in postnatal rat primary auditory neurons. Eur. J. Neurosci. 20, 2981-2989.

Florence, S. L., Hackett, T. A., and Strata, F. (2000). Thalamic and cortical contributions to neural plasticity after limb amputation. J. Neurophysiol. 83, 3154-3159.

Florence, S. L., Taub, H. B., and Kaas, J. H. (1998). Large-scale sprouting of cortical connections after peripheral injury in adult macaque monkeys. Science 282, 1117-1121.

Garraghty, P. E., Arnold, L. L., Wellman, C. L., and Mowery, T. M. (2006). Receptor autoradiographic correlates of deafferentation-induced reorganization in adult primate somatosensory cortex. J. Comp. Neurol. 497 636-645.
Garraghty, P.E.,Hanes, D.P., Florence, S.L., and Kaas, J. H. (1994). Pattern of peripheral deafferentation predicts reorganizational limits in adult primate somatosensory cortex. Somatosens. Mot. Res. 11, 109-117.

Garraghty, P. E., and Kaas, J. H. (1991). Large-scale functional reorganization in adult monkey cortex after peripheral nerve injury. Proc. Natl. Acad. Sci. U.S.A. 88, 6976-6980.

Garraghty, P. E., LaChica, E. A., and Kaas, J. H. (1991). Injury-induced reorganization of somatosensory cortex is accompanied by reductions in GABA staining. Somatosens. Mot. Res. 8, 347-354.

Garraghty, P. E., and Muja, N. (1996). NMDA receptors and plasticity in adult primate somatosensory cortex. J. Comp. Neurol. 367, 319-326.

Hagemann, G., Redecker, C., NeumannHaefelin, T., Freund, H.-J., and Witte, O. W. (1998). Increased longterm potentiation in the surround of experimentally induced focal cortical infarction. Ann. Neurol. 44, 255-258.

Ho, M. T., Pelkey, K. A., Topolnik, L. Petralia, R. S., Takamiya, K., Xia, J., Huganir, R. L., Lacaille, J. C., and McBain, C. J. (2007). Developmental expression of $\mathrm{Ca} 2+$-permeable AMPA 
receptors underlies depolarizationinduced long-term depression at mossy fiber CA3 pyramid synapses. J. Neurosci. 27, 11651-11662.

Hou, Q., Zhang, D., Jarzylo, L., Huganir, R. L., and Man, H.Y. (2008). Homeostatic regulation of AMPA receptor expression at single hippocampal synapses. Proc. Natl. Acad. Sci. U.S.A. 105, 775-780.

Ju, W., Morishita, W., Tsui, J., Gaietta, G., Deerinck, T. J., Adams, S. R., Garner, C. C., Tsien, R. Y., Ellisman, M. H., and Malenka, R. C. (2004). Activity-dependent regulation of dendritic synthesis and trafficking of AMPA receptors. Nat. Neurosci. 7, 244-253.

Kaas, J. H., Florence, S. L., and Jain, N. (1999). Subcortical contributions to massive cortical reorganizations. Neuron 22, 657-660.

Kozin, F., McCarty, D. J., Sims, J., and Genant, H. (1976). The reflex sympathetic dystrophy syndrome I. Clinical and histologic studies: evidence for bilaterality, response to corticosteroids and articular involvement. Am. J. Med. 60, 321-331.

Kumar, S. S., Bacci, A., Kharazia, V., and Huguenard, J. R. (2002). A developmental switch of AMPA receptor subunits in neocortical pyramidal neurons. J. Neurosci. 22, 3005-3015.

Maren, S., Tocco, G., Standley, S., Baudry, M., and Thompson, R. F. (1993). Postsynaptic factors in the expression of long-term potentiation (LTP): increased glutamate receptor binding following LTP induction in vivo. Proc. Natl. Acad. Sci. U.S.A. 90, 9654-9658.

Merzenich, M. M., Kaas, J. H., Wall, J., Nelson, R. J., Sur, M., and Felleman, D. (1983a). Topographic reorganization of somatosensory cortical areas $3 \mathrm{~b}$ and 1 in adult monkeys following restricted deafferentation. Neuroscience 8, 33-55.

Merzenich, M. M., Kaas, J. H., Wall, J. T., Sur,M.,Nelson, R.J., and Felleman, D. J. (1983b). Progression of change following median nerve section in the cortical representation of the hand in areas $3 \mathrm{~b}$ and 1 in adult owl and squirrel monkeys. Neuroscience 10, 639-665.

Merzenich, M. M., Nelson, R. J., Stryker, M. P., Cynader, M. S., Schoppmann, A., and Zook, J. M. (1984). Somatosensory cortical map changes following digit amputation in adult monkeys. J. Comp. Neurol. 224, 591-605.

Muñoz, A., Woods, T. M., and Jones, E. G. (1999). Laminar and cellular distribution of AMPA, kainate, and NMDA receptor subunits in monkey sensory-motor cortex. J. Comp. Neurol. 407, 472-490.

Myers, W. A., Churchill, J. D., Muja, N., and Garraghty, P. E. (2000). Role of NMDA receptors in adult primate cortical somatosensory plasticity. J. Comp. Neurol. 418, 373-382.

Oaklander, A. L., and Belzberg, A. J. (1997). Unilateral nerve injury downregulates mRNA for $\mathrm{Na}+$ channel SCN10A bilaterally in rat dorsal root ganlia. Mol. Brain Res. 52, 162-165.

Oaklander, A. L., and Brown, J. M. (2004). Unilateral nerve injury produces bilateral loss of distal innervation. Ann. Neurol. 55, 639-644.

Osborne, M. C., Verhovshek, T., and Sengelaub, D. R. (2007). Androgen regulates trkB immunolabeling in spinal motoneurons. J. Neurosci. Res. $85,303-309$.

Pons, T.P., Garraghty, P.E., Ommaya, A. K., Kaas, J. H., Taub, E., and Mishkin, M. (1991). Massive cortical reorganization after sensory deafferentation in adult macaques. Science 252, 1857-1860.

Recanzone, G. H., Merzenich, M. M., Jenkins, W. M., Grajski, K. A., and Dinse, H. R. (1992). Topographic reorganization of the hand representation in cortical area $3 \mathrm{~b}$ owl monkeys trained in a frequency-discrimination task. J. Neurophysiol. 67, 1031-1056.

Schroeder, C. E., Seto, S., and Garraghty, P. E. (1997). Emergence of radial nerve dominance in median nerve cortex after median nerve transection in an adult squirrel monkey. J. Neurophysiol. 77, 522-526.

Sur, M., Nelson, R.J., and Kaas, J.H. (1982). Representations of the body surface in cortical areas $3 \mathrm{~b}$ and 1 of squirrel monkeys: comparisons with other primates. J. Comp. Neurol. 211, 177-192.

Sutton,M.A.,Ito,H.T.,Cressy, P.,Kempf, C., Woo, J.C., and Schuman, E. M. (2006). Miniature neurotransmission stabilizes synaptic function via tonic suppression of local dendritic protein synthesis. Cell $125,785-799$.

Takahashi, T., Svoboda, K., and Malinow, R. (2003). Experience strengthening transmission by driving AMPA receptors into synapses. Science 299, 1585-1588.

Thiagarajan, T. C., Lindskog, M., and Tsien, R. W. (2005). Adaptation to synaptic inactivity in hippocampal neurons. Neuron 47, 725-737.

Tocco, G., Maren, S., Shors, T. J., Baudry, M., and Thompson, R. F. (1992). Long-term potentiation is associated with increased [3H]AMPA binding in rat hippocampus. Brain Res. 573, 228-234.

Vergara-Aragon, P., Gonzalez, C. L., and Whishaw, I. Q. (2003). A novel skilled-reaching impairment in paw supination on the "good" side of the hemi-Parkinson rat improved with rehabilitation. J. Neurosci. 23 , 579-586.

Wellman, C.L.,Arnold,L.L., Garman, E E., and Garraghty, P. E. (2002). Acute reductions in GABAA receptor binding in layer IV of adult primate somatosensory cortex after peripheral nerve injury. Brain Res. 954, 68-72.

Wierenga, C. J., Ibata, K., and Turrigiano, G. G. (2005). Postsynaptic expression of homeostatic plasticity at neocortical synapses. J. Neurosci. 25, 2895-2905.

Wilber, A. A., Southwood, C. J. Sokoloff, G., Steinmetz, J. E., and Wellman, C. L. (2007). Neonatal maternal separation alters adult eyeblink conditioning and glucocorticoid receptor expression in the interpositus nucleus of the cerebellum. Dev. Neurobiol. 67, 1751-1764.

Wilber, A. A., Southwood, C. J., and Wellman, C. L. (2009). Brief neonatal maternal separation alters extinction of conditioned fear and corticolimbic glucocorticoid and NMDA receptor expression in adult rats. Dev. Neurobiol. 69, 73-87.

Wright, N., Glazewski, S., Hardingham, N., Phillips, K., Pervolaraki, E., and Fox, K. (2008). Laminar analysis of the role of GluR1 in experiencedependent and synaptic depression in barrel cortex. Nat. Neurosci. 11, $1140-1142$

Xerri,C.,Stern,J.M., andMerzenich, M. M. (1994). Alterations of the cortical representation of the rat ventrum induced by nursing behavior. J. Neurosci. 14, 1710-1721.

Conflict of Interest Statement: The authors declare that the research was conducted in the absence of any commercial or financial relationships that could be construed as a potential conflict of interest.

Received: 10 October 2008; paper pending published: 26 November 2008; accepted: 13 January 2009; published online: 03 February 2009.

Citation: Mowery TM and Garraghty PE (2009) Nerve injury-induced changes to GluR1 and GluR2/3 subunit expression in area $3 b$ of adult squirrel monkeys: developmental recapitulation? Front. Syst. Neurosci. (2009) 3:1. doi: 10.3389/neuro.06.001.2009

Copyright $\odot 2009$ Mowery and Garraghty. This is an open-access article subject to an exclusive license agreement between the authors and the Frontiers Research Foundation, which permits unrestricted use, distribution, and reproduction in any medium, provided the original authors and source are credited. 